\title{
The Virtuous Circle: Increasing Diversity in LIS Faculties to Create More Inclusive Library Services and Outreach
}

\author{
By Dr. Paul T. Jaeger, University of Maryland \\ and Dr. Renee E. Franklin, Syracuse University
}

\begin{abstract}
While increasing the diversity of the library profession has been a long-running concern of Library and Information Science (LIS), the diversity of LIS doctoral students and faculties has received far less attention. This paper argues that libraries will be best equipped to provide inclusive services and outreach to diverse populations when LIS doctoral students and faculties better reflect the diversity of the United States population. After a brief overview of efforts to diversify LIS, this paper examines the current state of faculty diversity. The concept of a "virtuous circle" is then introduced, examining the ways in which an increase in faculty diversity can ultimately lead to more culturally aware LIS graduates whose education will prepare them to help libraries provide inclusive services and outreach to diverse communities of patrons. The paper then discusses ways that LIS programs and LIS research can work to create this virtuous circle to promote diversity and inclusiveness in LIS.
\end{abstract}

\section{Introduction}

A major concern in Library and Information Science (LIS) for many years has been developing ways to address diversity, or lack thereof, within the profession (Bonnici \& Burnett, 2005; Josey, 1993; Lance, 2005; Wheeler, 2005). Quite often, the focus has been on recruiting and retaining ethnically diverse master's students in an attempt to produce a larger pool of ethnically diverse librarians. "During periods of intensified recruitment, the profession as a whole will focus on MLS students" (Gollop, 1999, 389) and, as a result, the diversity of LIS faculties receives much less attention than other diversity issues. However, the very low levels of diversity among LIS faculty have far-reaching impacts for LIS education and library services. In school media centers and other education libraries, diversity and inclusiveness are major concerns (Buddy \& Williams, 2005). This paper argues that increasing diversity in LIS faculties is essential to expanding the inclusiveness of library services for diverse populations and bringing those services to diverse populations.

Most examinations of the benefits of diversity and inclusiveness in LIS similarly focus exclusively on the library of practitioners. "In the circular, self-cycling style of education and librarianship, minority school and public librarians who serve as role models for minority children may inspire the children to go to college. In college, minority academic librarians and library school faculty may inspire them to go to graduate school to become librarians and role models themselves" (Totten, 2000, 16). However, such perspectives do not account for the vital importance of diverse faculty teaching master's students about inclusive library services and the ways to reach diverse communities of patrons. The lack of consideration of faculty diversity in discussion of library diversity is surprisingly commonplace. In a 2004 essay entitled "What Ails Library Education?," then soon-to-be American Library Association President Michael Gorman discusses the limited diversity among library professionals and in library services without once indicating that limited diversity in LIS faculty might be a part of these issues (Gorman, 2004).

LIS programs are hardly unique in the limited diversity of their faculties. Nationwide, many fields struggle with achieving a representative faculty population (Smith \& Moreno, 2006). The issue is particularly pressing in LIS, though, as graduates of LIS programs will immediately begin working in environments where they will have to understand and meet the information needs of diverse populations. In order to produce inclusive library services for all populations, LIS needs to work at creating a virtuous circle of inclusiveness. Due to the current preponderance of white faculty in LIS programs, the range of perspectives that LIS Master's students are exposed to can be quite limited, particularly in terms of providing inclusive library services to diverse populations. 
If more faculty members in LIS programs are from diverse and under-represented populations, their perspectives and voices will help to shape the content of curriculum and instruction in LIS Master's programs to be more inclusive of diverse perspectives. This, in turn, will produce graduates of LIS Master's programs who will be more aware of the needs of diverse populations of library patrons and better prepared to provide inclusive services to their communities. Increased levels of diversity among LIS faculty will also help to reinforce to Master's students from under-represented populations that they too can become LIS faculty, leading to more diversity in LIS doctoral programs and producing more library administrators and LIS faculty from diverse backgrounds. Ultimately, this circle of diversity in LIS programs will result in more inclusive services to all library patrons in all types of libraries.

\section{Current Levels of Diversity among LIS Faculty Members and Library Professionals}

LIS doctoral programs consistently have very few African American and Latino students enrolled in or completing programs of study. The most recent ALISE statistics indicate that the LIS professoriate continues to lack representative diversity, especially for African Americans and Latinos (Sineath, 2005). Only $3.7 \%$ of the full-time faculty members are Latino, as compared to $14.5 \%$ of the total population, while African Americans comprise just $5.5 \%$ of the full-time faculty as compared to $12.1 \%$ of the population (Sineath, 2005). In 2002-2003, of the 82 LIS doctoral degrees awarded, only two were awarded to African Americans and one to a Latino (Sineath, 2005). As a result, the faculty population in LIS has remained fairly stable in its level of diversity, with the percentage of African Americans and Latinos in LIS faculties changing little since the passage of the Civil Rights Act in the 1960s (Josey, 1993). This limited diversity among LIS faculty is paralleled in the population of librarians, with only $3.3 \%$ of librarians being Latino and only $6.0 \%$ being African American (Lance, 2005).

Over time, these discrepancies in representation mount in consequence. For example, since 1993, only 42 of the 612 doctoral degree recipients from ALA-accredited LIS Schools in the United States were African Americans, or $6.8 \%$ of the total number of LIS Ph.D. graduates during this time period (Franklin \& Jaeger, under review). Put another way, the total number of African Americans receiving a Ph.D. in LIS since 1993 is about half of the number of whites who received a Ph.D. in LIS in the year 2003 alone (Franklin \& Jaeger, under review). Further, just a handful of LIS programs account for the majority of these African American and Latino doctoral program graduates (Franklin \& Jaeger, under review). The very small number of African Americans and Latinos being awarded doctoral degrees means there are few African American or Latino directors of major library systems and faculty members teaching future librarians and researchers. As such, limited diversity among LIS faculty may be a fairly sizeable detriment to LIS programs as a whole.

Latinos and African Americans are respectively the second and third largest ethnic populations in the United States, and Latinos are the fastest growing segment of the United States population, projected to comprise $24.4 \%$ of the U.S. population by 2050 (Lance, 2005; Winston \& Walstad, 2006). As such, it is imperative for libraries to be able to meet the information needs and provide the resources, services and training required by these populations of patrons. However, the numbers of African American and Latino librarians are far below those necessary to be representative of the national population (Lance, 2005). This lack of representation in librarianship was recently the subject of an Associated Press article that was published in major national newspapers like the Washington Post (Thomas, 2007).

This discussion focuses on African Americans and Latinos because they are the two largest minority populations in the United States and the two populations most sorely under-represented among LIS faculty and librarians (Lance, 2005; Sineath, 2005). While Native Americans comprise less than $1 \%$ of librarians and LIS faculty, they also are less than $1 \%$ of the total U.S. population, with statistically very similar representation in LIS, libraries, and the general population (Adkins \& Espinal, 2004; Lynch, 2000). Likewise, the percentages of Asian Americans and Pacific Islanders in the general population and among librarians are very similar, and their representation among LIS faculty is higher than among the general population (Lance, 2005; Sineath, 2005). As such, the key to increasing diversity among LIS faculty and librarians, and thereby providing more inclusive library services to diverse populations, is improving the representation of African Americans and Latinos in LIS faculties. 


\section{The Virtuous Circle: The Importance of Diverse LIS Faculties}

LIS programs "must accept responsibility for populating the profession with a new generation of culturally competent librarians" (Wheeler, 2005, 184). However, culturally competent librarians can only be educated by a diverse faculty offering diverse perspectives on information and work in library systems with diverse leadership. A key part of this problem is developing a better understanding of why more members of under-represented populations, African Americans and Latinos in particular, do not choose to get doctoral degrees in LIS.

One reason may be related to the social networks that impact why individuals chose a particular occupation. Many people-family members, friends, teachers, counselors, and other role models, among others-have an impact on the decision of an individual to join a field (Winston, 1998). A study conducted in 2006 showed that a majority (57\%) of librarians of color responding to the survey "made it clear that having more faculty of color in the LIS school/program and having faculty/staff/alumni of color involved in the recruitment process would attract more students of color" (Kim \& Sin, 2006, 89). A main recommendation for increasing student diversity by the respondents to the same survey was to have greater faculty diversity (Kim \& Sin, 2006). A 2005 study found that students from diverse populations "report that the presence of minority faculty members in their academic discipline is a critical factor in their recruitment, retention, and success at all levels" (Neely, 2005, 98). These findings indicate that the current level of limited faculty diversity becomes self perpetuating when there are an insufficient number of mentors available from under represented populations.

There are several very significant reasons to work to increase the diversity of LIS faculties as a means of better preparing LIS Master's students to meet the needs of under-represented populations in libraries and of increasing the inclusiveness of library services.

- Increasing the diversity in LIS faculties is necessary to broaden the number of perspectives in teaching, research, service, leadership, and administration, better reflecting the diverse patrons of libraries in the United States.

- A lack of faculty members from under-represented populations will serve to perpetuate a lack of diversity in LIS as a whole.

- Faculty members from under-represented populations in predominantly white faculties are vital as recruiters, mentors, and mediators for students from under-represented populations (Totten, 2000).

- Colleges and corporations that are the most diverse are often highly regarded and highly successful (Winston \& Walstad, 2006).

- Faculty diversity encourages the use of a broader range of pedagogical techniques and increases faculty-student interaction (Umbach, 2006).

Ultimately, without greater diversity in LIS faculties, graduates of LIS Master's programs will be insufficiently prepared to meet the diverse information needs of and provide inclusive community outreach to all of the cultures that use libraries in the United States.

Within this context, diversity of LIS faculties and doctoral populations receives surprisingly little consideration. This is supported by Wheeler's (2005) statement that "realistically, there is no need for research regarding the re-segregation of library schools. Statically speaking, there are few, if any, that have ever truly integrated" (vii). While the Institute of Museum and Library Services, the American Library Association, the Special Library Association, the American Association of Law Librarians, Association of Research Libraries, the Medical Library Association, and many state library associations, among others, have employed a wide range of programs to promote diversity among library professionals (Kim \& Sin, 2006; McCook, 2000; McCook \& Geist, 1993), there have been only a few attempts to foster diversity among LIS faculty at individual schools. Project Athena (http://www.projectathena.ci.fsu.edu/aboutus.htm) a grant funded project jointly conceived by researchers at Florida State University, University of Illinois at UrbanaChampaign, University of Washington, and University of North Carolina at Chapel Hill, was created to support the development of current minority doctoral students (Bonnici \& Burnett, 2005). Recently, the University of North Carolina established a program for minority post-doctoral fellows to support their research as beginning faculty members. However, these programs have not studied the reasons for the limited number of minority doctoral students in LIS, the impacts of these low numbers on the preparation 
of LIS Master's students to meet the information needs of diverse patrons in libraries, or ways to increase the presence of diverse populations in LIS faculties and professions. A further complication is that the LIS programs with the most diverse student populations may not be ones that have Ph.D. programs (McCook \& Lippincott, 1997).

With more African American and Latino graduates of LIS doctoral programs, there will be more African American and Latino LIS faculty and library administrators and directors. A greater diversity in LIS faculties will lead to more inclusive education about the perspectives and information needs of African Americans and Latinos. In 1993, E .J. Josey asserted that "minority faculty is the key to success" in bringing diversity to the profession and meeting the information needs of diverse populations (305). With greater faculty diversity, all LIS Master's graduates will be better prepared to meet the information needs of diverse populations of library patrons. As Figure 1 shows, a greater diversity in library directors and administrators will ensure that libraries of all types are better able to meet the information needs of diverse populations of patrons.

Figure 1: The virtuous circle: the relationships between faculty diversity and inclusive library services

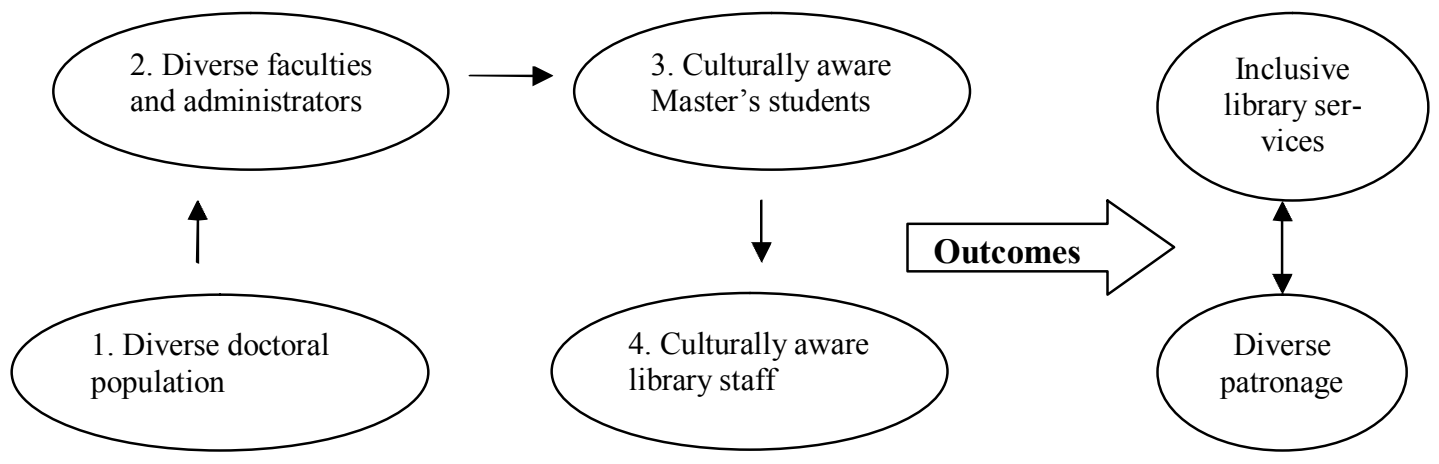

To achieve vital national impacts, research must identify the reasons for the traditional low levels of participation of under-represented populations in LIS doctoral programs, and the ways to increase their participation must be identified and implemented. Studies must be conducted that address such important gaps in the understanding of the roles of minority doctoral students, faculty members, and professional leaders in preparing LIS Master's students and libraries to provide inclusive library services to diverse patron populations.

\section{From Diverse Faculties to Inclusive Services Reaching Diverse Patron Communities}

Issues of diversity and inclusion can affect library services in any type or size of library (i.e., Wheeler, 2005b, Whitmire, 1999, 2003). However, libraries within educational institutions (e.g. K-12 schools and college and university campuses) may be particularly in need of inclusive services because most are serving very diverse patron populations (Strizek, Pittsonberger, Riordan, Lyter, \& Orlofsky, 2006). As patrons come from diverse backgrounds, these education libraries need to design programs and services around the diverse needs of patrons of different backgrounds (Whitmire, 1999). One study of academic libraries found that students of color reported more academic library use, indicating the success of outreach programs to diverse populations by academic libraries (Whitmire, 2003). Such findings indicate the need for such outreach programs in all other types of libraries. Greater diversity among LIS faculty will ultimately be instrumental in ensuring inclusive services, programs, and outreach in libraries.

To truly reach all communities of patrons, outreach programs need to be based on inclusive services and understanding of perspectives of diversity. This inclusiveness must be incorporated into the classes and academic environments that comprise an MLS degree, both in the content of courses and the members of the faculty. Inclusive services need to be an aspect of all classes in a Master's degree program, not just one elective (Belay, 1992; Nilsen, 2004). "Ideally, diversity should be integrated across the curriculum, within each course offered" (Neely, 2005, 98). Similarly, inclusive outreach to diverse communities of patrons needs to be a component of every LIS course. If reaching diverse communities of patrons was an 
element of LIS courses, new librarians would enter the profession immediately prepared to provide inclusive community outreach.

Along with the concept of promoting inclusive services to patrons, LIS programs can also emphasize inclusive outreach in the curriculum by expanding the role of language in the curriculum. The lack of inclusiveness in LIS programs is reflected in lack of education in languages in LIS schools, even though most libraries serve multi-lingual populations at this point (Jorma, 2002). Inclusive outreach to diverse communities will be greatly improved by librarians versed not only in the information needs of diverse populations, but also familiar with the languages of these populations. At present, acceptance and "knowledge of other languages and cultures has been dismissed or overlooked as unimportant" (Adkins \& Espinal, 2004, 54) within LIS. At a minimum, given the rapidly increasing numbers of Latinos in the United States, encouraging LIS students to have basic fluency in Spanish seems beneficial for making strides toward achieving the goal of promoting inclusive information provision services. Currently practicing librarians can be of great help in determining how individual library schools can best teach inclusive services for diverse populations. It has been noted that alumni of LIS programs from under-represented populations can be very important in encouraging greater inclusiveness at LIS programs (Knowles, 2005). Similarly, librarians working in the geographic areas where the graduates of a specific LIS program tend to seek employment can be a tremendous resource in helping a school determine what populations' information needs should receive more attention in the curriculum. Currently practicing librarians will be in an optimal position to identify the communities that most frequently use libraries in an area and the types of community outreach that have been most successful in a particular area.

An overall goal of increasing diversity in the LIS profession has been to introduce more perspectives into "library decision making, administration, and library services," and to "better reflect the multicultural community that is being served and offer an environment that is more open, receptive, and conducive to the success" of all library patrons and employees (Winston, 1998, 1). In that same spirit, increasing the diversity of LIS faculty will greatly help to expand the inclusiveness of education in library programs and the preparation of LIS graduates to offer inclusive services to diverse communities of patrons.

\section{Conclusions: Implications for Practice and Research}

To move toward the goal of creating more diversity within LIS, research must be conducted to identify the reasons for the traditionally low levels of participation of African Americans and Latinos in LIS doctoral programs, and the ways to increase their participation must be identified and implemented in ensure increases in the diversity of LIS faculties. Research that focuses on uncovering the perspectives of these cultural groups will allow for:

- increased understanding of the reasons that African Americans and Latinos enter LIS;

- documentation of African American's and Latino's unique experiences during matriculation and after graduation;

- increased understanding about African American's and Latino's attitudes about the LIS field;

- documentation of African American's and Latino's feelings about levels of inclusion in the field;

- documentation of African American's and Latino's perceptions of LIS programs with exemplary methods of preparing Master's graduates to serve diverse user populations; and

- documentation of African American's and Latino's perceptions about the impact of diversity on inclusive library services issues of diversity and inclusion in LIS programs from a range of different perspectives.

Recording these unique perspectives is vital to the multicultural success of LIS programs and libraries.

Research findings such as these can help establish the ways in which LIS programs can further the virtuous circle of diverse faculties that will lead to more diverse student populations, more culturally aware graduates, and more inclusive library services and outreach programs for the diverse communities of patrons that rely on libraries in the United States. More inclusive services and outreach will, in turn, draw more diverse users to libraries.

Along with conducting research about the specific nature of diversity in LIS faculties, LIS programs can also turn to the efforts to increase faculty diversity in other disciplines and by particular institutions for 
ideas. Studies have attempted to document both successful methods for attracting and retaining faculty candidates from diverse populations, as well as to identify methods that have proven unsuccessful (e.g., Ingle, 2006; Piercy, Giddings, Allen, Dixon, Meszaros, \& Joest, 2005). Certain institutions of higher education have also worked to develop comprehensive policies and practices to attract and retain diverse faculty candidates (e.g., McGarvey, 2007). A comprehensive review and study of the methods used by other disciplines to increase faculty diversity may suggest policies and practices that might have a positive impact on the diversity of LIS faculties.

Education-related libraries have significant reasons to be attentive to these issues and can play a role in raising awareness about these issues among LIS faculties. School library media centers and children's services in public libraries are often the first libraries that children truly experience. Inclusive library services and outreach in these types of libraries are vital to drawing all children into learning to use the library and its resources. Education libraries within post-secondary institutions can provide a stimulating learning environment that can lead to immediate career exploration. Inclusive libraries will also help to open up young from diverse backgrounds to the idea that they may want to work in a library one day or even become a library educator. Given the essential role of education and other youth-serving libraries in helping to form relationships between young learners and libraries, there can be effective advocates among all libraries for the need for inclusive services and outreach, as well as an emphasis in LIS on ensuring that diverse faculties will be present to teach future librarians.

To fulfill libraries' social mission as provider of equal services to all, library services and outreach that are inclusive to diverse communities of patrons are becoming even more important as the United States becomes increasingly more diverse. There are many steps at many different levels that can be taken to help ensure inclusive outreach and services in libraries. Members of diverse populations are "waiting in the wings to be invited and encouraged to join the professional ranks of librarianship" (Josey, 1999, 201). An emphasis on LIS programs and LIS research to create a virtuous circle to promote diversity and inclusiveness in LIS, however, will be needed to ensure that diversity and inclusiveness are central to both LIS education and library services.

Acknowledgement: The authors would like to thank Kathleen Burnett of the College of Information at Florida State University for her helpful comments during the development of this paper.

\section{References}

Adkins, D., \& Espinal, I. (2004). The diversity mandate. Library Journal, 45(2). 149-161.

Belay, G. (1992). Conceptual strategies for operationalizing multicultural curricula. Journal of Education for Library and Information Science, 33, 295-306.

Bonnici, L., \& Burnett, K. (2005). A web model of recruitment for LIS Doctoral Education: Weaving in diversity. In M. B. Wheeler (Ed.), Unfinished business: Race, equity, and diversity in library and information science education (pp. 119-130). Lantham, MD: Scarecrow Press.

Buddy, J., \& Williams, M. (2005). A dream deferred: School libraries and segregation. American Libraries, 36(2), 33-35.

Franklin, R. E., \& Jaeger, P. T. (under review). A decade of doctorates: An examination of dissertations written by African American females in Library and Information Studies 1993-2003.

Gollop, C. J. (1999). Library and information science education: Preparing future librarians for a multicultural society. College and Research Libraries, 60(4), 385-395.

Gorman, M. (2004). What ails library education? Journal of Academic Librarianship, 30(2), 99-101.

Ingle, G. M. (2006). How not to diversify the campus work force. Chronicle of Higher Education, 53(6), 25.

Jorma, K. (2002). Educating information professionals in a multicultural information society. Library Review, 51(3/4), 157-163.

Josey, E. J. (1993). The challenges of cultural diversity in the recruitment of faculty and students from diverse backgrounds. Journal of Education for Library and Information Science, 34, 302-311.

Josey, E. J. (1999). Diversity: Social and political barriers. Journal of Library Administration, 27(1/2), 191201.

Kim, K., \& Sin, S. (2006). Recruiting and retaining students of color in LIS programs. Journal of Education for Library and Information Science, 47(2), 81-95. 
Knowles, E. (2005). Affirmative action: The role of the dean. In M. Wheeler (Ed.), Unfinished business: Race, equity, and diversity in library and information science education. Lantham, MD: Scarecrow.

Lance, K. C. (2005). Racial and ethnic diversity of U.S. library workers. American Libraries, 36(5): 41-43.

Lynch, M. J. (2000). What we now know about libraries. American Libraries, 31(2). 8-9.

McCook, K. \& Geist, P. (1993). Diversity deferred: where are the minority librarians? Library Journal, 118(18), 35-38.

McCook, K. \& Lippincott, K. (1997). Library schools and diversity: Who makes the grade? Library Journal, 122(7), 30-32.

McCook, K. (2000). Introduction. Library Trends, 49(1), 1-5.

McGarvey, K. (2007). A new look at diversity. Rochester Review, 69(3). Retrieved April 20, 2007, from http://www.rochester. edu/pr/Review/V69N3/feature1.html

Neely, T. (2005). Minority student recruitment in LIS education. In M. Wheeler (Ed.), Unfinished business: Race, equity, and diversity in library and information science education. Lantham, MD: Scarecrow.

Nilsen, K. (2004). LIS education for multiculturalism and diversity. Feliciter, 50(1), 17-18.

Piercy, F., et al. (2005). Improving campus climate to support faculty diversity and retention: A pilot program for new faculty. Innovative Higher Education, 30(1), 53-66.

Sineath, T. (2005). Faculty, in E. Daniel, \& J. Saye (Eds.), ALISE Library and Information Science Education Statistical Report 2004. Oakridge, TN: Association for Library and Information Science Education.

Smith, D. G., \& Moreno, J. F. (2006). Hiring the next generation of professors: Will myths remain excuses? Chronicle of Higher Education, 53(6), 22.

Strizek, G.A., Pittsonberger, J.L., Riordan, K.E., Lyter, D.M., and Orlofsky, G.F. (2006). Characteristics of schools, districts, teachers, principals, and school libraries in the United States: 2003-04 Schools and Staffing Survey (NCES 2006-313 Revised). Washington, DC: U.S. Government Printing Office.

Thomas, A. (2007, January 7). A new chapter for librarians. Washington Post, A13.

Totten, H. L. (2000). Ethnic diversity in library schools: Completing the education cycle. Texas Library Journal, 76(1), 16-19.

Umbach, P. D. (2006). The contribution of faculty of color to undergraduate education. Research in Higher Education, 47(3), 317-345.

Wheeler, M. B. (2005a). Faculty development and cultural diversity in teaching: LIS education's last frontier. In M. B. Wheeler (Ed.), Unfinished business: Race, equity, and diversity in library and information science education (pp. 181-192). Lantham, MD: Scarecrow Press.

Wheeler, M. B. (2005b). Unfinished business: Race, equity, and diversity in library and information science education. Lantham, MD: Scarecrow Press.

Wheeler, M. B. (2005c). Foreword. In M. B. Wheeler (Ed.), Unfinished business: Race, equity, and diversity in library and information science education (pp. vii-ix). Lantham, MD: Scarecrow Press.

Whitmire, E. (1999). Racial differences in the academic library experiences of undergraduates. The Journal of Academic Librarianship, 25(1), 33-37.

Whitmire, E. (2003). Cultural diversity and undergraduates' academic library use. The Journal of Academic Librarianship, 29(3), 148-161.

Winston, M. (1998). The role of recruitment in achieving goals related to diversity. College and Research Libraries, 59(3), 240-247.

Winston M., \& Walstad, K. (2006). Recruitment and diversity: A research study of bilingualism and library services. Library \& Information Science Research, 28, 390-406.

Paul T. Jaeger, Ph.D., J.D., is an Assistant Professor at the College of Information Studies at the University of Maryland. His research focuses on the ways in which law and public policy shape access to information. Dr. Jaeger is the author of more than forty journal articles and book chapters, along with three books. He has written extensively on issues of equal access to information, particularly for persons with disabilities. Email: pjaeger@umd.edu

Renee E. Franklin, Ph.D., is an Assistant Professor at the School of Information Studies at Syracuse University. Her research involves investigating a variety of LIS education issues, including school library media administration, media specialist preparation, intellectual freedom, and diversity within LIS graduate programs. With regard to issues of diversity, Dr. Franklin is particularly interested in examining the experiences of minority students in LIS graduate programs and factors affecting minority LIS faculty's career success. Email: rfranklin@ci.fsu.edu 